\title{
Synthesis and Characterization of a Lipidic Alpha Amino Acid: Solubility and Interaction with Serum Albumin and Lipid Bilayers
}

Hugo A. L. Filipe, ${ }^{\dagger}$ Filipe M. Coreta-Gomes, ${ }^{\dagger}$ Adrian Velazquez-Campoy, $^{\ddagger}{ }^{\S}$ Ana R. Almeida, ${ }^{\dagger}$ Andreia F. Peixoto, ${ }^{\dagger}$ Mariette M. Pereira, ${ }^{\dagger}$ Winchil L. C. Vaz, ${ }^{\dagger}$ and Maria J. Moreno ${ }^{*}{ }^{\dagger}$

${ }^{\dagger}$ Departamento de Química, Universidade de Coimbra, 3004-535 Coimbra, Portugal

${ }^{\ddagger}$ Institute of Biocomputation and Physics of Complex Systems (BIFI), Universidad de Zaragoza, Unidad Asociada BIFI-IQFR, CSIC, Zaragoza, Spain

${ }^{\S}$ Fundación ARAID, Diputación General de Aragón, Spain

\section{Supporting Information}

ABSTRACT: The lipidic $\alpha$-amino acid with 11 carbons in the alkyl lateral chain ( $\alpha$-aminotridecanoic acid) was synthesized via multicomponent hydroformylation/Strecker reaction, which is a greener synthetic approach to promote this transformation relative to previously described methods. Its solubility and aggregation behavior in aqueous solutions was characterized, as well as the interaction with lipid bilayers. Lipidic amino acids are very promising molecules in the development of prodrugs with increased bioavailability due to the presence of the two polar functional groups and nonpolar alkyl chain. They are also biocompatible surfactants that may

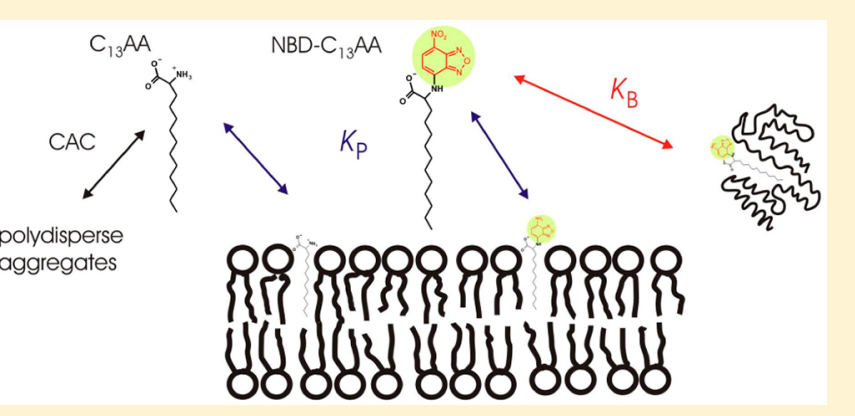
be used in the food and pharmaceutical industry. In this work we have conjugated the lipidic amino acid with a fluorescent polar group (7-nitrobenz-2-oxa-1,3-diazol-4-yl), to mimic drug conjugates, and its association with serum proteins and lipid bilayers was characterized. The results obtained indicate that conjugates of polar molecules with lipidic $\alpha$-amino acid, via covalent attachment to the amine group, have a relatively high solubility in aqueous solutions due to their negative global charge. They bind to serum albumin with intermediate affinity and show a very high partition coefficient into lipid bilayers in the liquiddisordered state. The attachment of the polar group to the lipidic amino acid increased strongly the aqueous solubility of the amphiphile, although the partition coefficient into lipid membranes was not significantly reduced. Conjugation of polar drugs with lipidic amino acids is therefore an efficient approach to increase their affinity for biomembranes.

\section{INTRODUCTION}

Lipidic $\alpha$-amino acids have a long hydrocarbon chain in their lateral chain being significantly more hydrophobic than the common $\alpha$-amino acids found in proteins. They are considered non-natural, although $\alpha$-amino acids with very long hydrocarbons in the lateral chain (28 and 29 C) have been encountered in some cnidarians. ${ }^{1}$ The natural function of those lipidic $\alpha$-amino acids is not known, but they have been found to have cytotoxic activity toward tumor cell lines. ${ }^{1}$

The presence of the two functional groups in the lipidic amino acids makes them very interesting molecules in the design of prodrugs with increased bioavailability. Depending on the charge of the pharmacologically active moiety and on the preferred global charge, the lipidic amino acid may be attached to the polar drug via the amine or carboxylic acid group. Additionally, the metabolic stability of the resulting prodrug may be designed to fulfill the pharmacologic requirements from the labile ester bond to more stable covalent bonds involving the amine group. ${ }^{2}$ Covalent modification at the amine or carboxylic group will also lead to amphiphiles with distinct dipole moments. This property has been shown to influence the interaction of the amphiphile with biological membranes of distinct lipid composition ${ }^{3,4}$ and may be a relevant tool in the design of ligands targeted toward specific cells or membrane pools within the cell. The amphiphilic nature of the lipidic amino acids and their biocompatibility makes them interesting candidates as surfactants in the food and pharmaceutical industries. 5

The synthesis of non-natural amino acids has attracted special attention in recent years because they play an important role in the design and synthesis of new molecules with relevant properties. ${ }^{6}$ The Strecker synthesis, which is considered the first multicomponent reaction, is a versatile and cheap method to synthesize racemic $\alpha$-amino acids, where the aldehyde is one of the three starting components. ${ }^{7}$ Nowadays, hydroformylation, a reaction catalyzed by organometallic complexes, is considered one of the best approaches to convert alkenes into higher value aldehydes. $^{8}$ So, the combination of these two reactions in a

Received: August 8, 2012

Revised: $\quad$ March 11, 2013

Published: March 11, 2013 
one-pot hydroformylation/Strecker was recently described by Eilbracht as an attractive synthetic tool for the preparation of $\alpha$ amino nitriles, which are important amino acid precursors. 9

Lipidic $\alpha$-amino acids have been used previously as conjugates of very polar pharmacologically active molecules in an attempt to improve their bioavailability due to the increased hydrophobicity. ${ }^{10-17}$ The results obtained show a significant increase in the blood concentration after oral administration, ${ }^{12}$ in the rate of permeation through Caco-2 cell monolayers ${ }^{14}$ and in the rate of cell uptake ${ }^{12}$ for some drug conjugates. However, the overall trend is very difficult to interpret as it does not follow any predictable dependence on the structure of the lipidic amino acid. ${ }^{10,12}$ This may be partially due to the existence of specific transporters and efflux pumps or even due to distinct rates of degradation by the cells. In addition, the interpretation of the results is hampered by the lack of a previous characterization of the physicochemical properties of the lipidic amino acids and their conjugates. In spite of the wide use of the different lipidic amino acids, mostly by Toth and coworkers, the aqueous solubility has been reported only for the glucose conjugate of $\alpha$-aminotridecanoic acid. ${ }^{15}$ The interaction of some drug conjugates of lipidic amino acids with DPPC bilayers has also been qualitatively evaluated experimentally and calculated using available software, ${ }^{13,16}$ but surprisingly, the results from the two approaches have not been critically compared.

The rate of passive permeation through confluent cell monolayers is usually considered to be proportional to the hydrophobicity of the solute, in agreement with the so-called "Overton rule". ${ }^{18}$ However, for very hydrophobic solutes, the rate of interaction with the membranes may become the rate limiting step in the overall permeation process, breaking down the premises of the Overton rule. ${ }^{19-22}$ The aggregation behavior of the amphiphilic drug and its relative affinity for proteins in the aqueous media and for the cell biomembranes are additional parameters that may lead to a nonmonotonic dependence of the rate of permeation on the amphiphile hydrophobicity. ${ }^{23}$ It is therefore very important to characterize the monomeric solubility of the lipidic amino acids and their drug conjugates as well as their interaction with serum proteins and biomembranes. The length of the hydrocarbon chain may also influence the location of the amphiphile in the lipid bilayer $^{24,25}$ with important consequences on the amphiphile acid-base equilibria and on the kinetic and equilibrium parameters for the interactions with lipid bilayers. ${ }^{20}$

In this paper we describe the efficient synthesis of a lipidic $\alpha$ amino acid with 11 carbons in the hydrophobic lateral chain $(\alpha$ aminotridecanoic acid) and its conjugation with the polar fluorescent group NBD (7-nitrobenz-2-oxa-1,3-diazol-4-yl). The solubility of the monomeric form and the aggregation behavior, in aqueous media at $\mathrm{pH}=7.4$, were studied as well as the interaction with serum albumin and lipid bilayers prepared from 1-palmitoyl-2-oleoyl-sn-glycero-3-phosphocoline (POPC). Qualitative information regarding the rate of interaction with the POPC lipid bilayers is also reported.

\section{MATERIALS AND METHODS}

2.1. Materials and Equipment. ${ }^{1} \mathrm{H}$ and ${ }^{13} \mathrm{C}$ NMR spectra were recorded in $\mathrm{CDCl}_{3}$ or $\mathrm{CD}_{3} \mathrm{OD}$ solutions on a Bruker 300 spectrometer, operating at $300.13 \mathrm{MHz}$ for ${ }^{1} \mathrm{H}$ and at 75.47 $\mathrm{MHz}$ for ${ }^{13} \mathrm{C}$. MS was carried out on Micromass Q-TOF 2 spectrometer containing a Z-spray source, an electrospray probe, and an injection syringe. GC was carried out on Agilent-
6890, equipped with capillary HP5 columns and a FID detector. $\mathrm{Rh}(\mathrm{acac})(\mathrm{CO})_{2}$, xantphos, and 1-undecene were purchased from Sigma Aldrich. Dimethoxyethane, used in the catalytic experiments, was purified by reflux over sodium lumps/benzophenone, for $8 \mathrm{~h}$, and then distilled. Steady state fluorescence measurements were performed on a Cary Eclipse fluorescence spectrophotometer (Varian) equipped with a thermostatted multicell holder. UV-vis absorption was performed on a Unicam UV530 spectrophotometer (Cambridge, U.K.). Calorimetry titrations were performed on a VPITC instrument from MicroCal (Northampton, MA, U.S.A.) with a reaction cell volume of $1410.9 \mu \mathrm{L}$ at $25^{\circ} \mathrm{C}$. The injection speed was $0.5 \mu \mathrm{L} \mathrm{s}^{-1}$, stirring speed was $459 \mathrm{rpm}$, and the reference power was 2 or $10 \mu \mathrm{cal} \mathrm{s}^{-1}$. The average size of the LUVs and their zeta potential was measured on a Malvern Nano ZS (Malvern Instruments, Malvern, U.K.).

2.2. Catalytic Experiments. The NMR spectra of the $\alpha$ lipidic amino acid, the NBD conjugate, and the synthesis intermediates are given in the Supporting Information.

2.2.1. General Procedure for One Pot HydroformylationStrecker Reaction. The catalyst $\mathrm{Rh}(\mathrm{acac})(\mathrm{CO})_{2}(0.01 \mathrm{mmol})$ with the ligand xantphos $(0.05 \mathrm{mmol})$ were placed in a glasslined stainless steel autoclave, which was closed and purged with three cycles of vacuum and a $\mathrm{CO} / \mathrm{H}_{2}$ equimolar mixture. A solution of 1-undecene $(5 \mathrm{mmol})$ in DME $(8 \mathrm{~mL})$ was added via cannula into the autoclave, which was pressurized again to 20 bar with a $\mathrm{CO} / \mathrm{H}_{2}$ equimolar mixture and then heated at 80 ${ }^{\circ} \mathrm{C}$. After $44 \mathrm{~h}$, the reactor was cooled to room temperature and a water solution $(2 \mathrm{~mL})$ of $\mathrm{NH}_{4} \mathrm{Cl}(10 \mathrm{mmol})$ and $\mathrm{NaCN}(10$ $\mathrm{mmol}$ ) was added via inlet cannula. The reaction was kept at room temperature for $1.5 \mathrm{~h}$ and then at $50{ }^{\circ} \mathrm{C}$ for $20 \mathrm{~h}$. Upon completion, the reaction mixture was washed with brine solution, extracted with diethyl ether, and the organic layer was dried $\left(\mathrm{Na}_{2} \mathrm{SO}_{4}\right)$ and evaporated. The residue was purified by silica gel column chromatography starting with $\mathrm{CH}_{2} \mathrm{Cl}_{2}$ as eluent, and solvent polarity was increased during the process by adding ethyl acetate, $\mathrm{CH}_{2} \mathrm{Cl}_{2}$ /ethyl acetate (2:1).

2-Aminotridecanonitrile, 3. ${ }^{1} \mathrm{H} \mathrm{NMR}\left(\mathrm{CDCl}_{3}, 300 \mathrm{MHz}\right)$, $\delta$, ppm: $0.88\left(\mathrm{t}, 3 \mathrm{H}, \mathrm{CH}_{3}\right), 1.19-1.38\left(\mathrm{~m}, 16 \mathrm{H}, \mathrm{CH}_{2}\right), 1.44-$ $1.53\left(\mathrm{~m}, 2 \mathrm{H}, \mathrm{CH}_{2}\right), 1.82\left(\mathrm{q}, 2 \mathrm{H}, \mathrm{CH}_{2}\right), 4.46(\mathrm{t}, 1 \mathrm{H}$, $\left.\mathrm{C}^{\mathrm{HNH}} \mathrm{H}_{2} \mathrm{CN}\right) .{ }^{13} \mathrm{C}$ NMR, $\delta$, ppm: 120.2 (CN), 61.3 $\left(\underline{\mathrm{CHNH}}_{2} \mathrm{CN}\right), 35.2-14.1\left(\mathrm{C}_{\text {alkyl }}\right)$.

2.2.2. General Procedure for Hydrolysis of 2-Aminotridecanonitriles. The appropriate aminonitrile (isolated from the one pot hydroformylation/Strecker reaction) was suspended in a concentrated $\mathrm{HCl}$ solution and stirred for $6 \mathrm{~h}$ at room temperature. The solid product was filtered and washed with water $(2 \times 50 \mathrm{~mL})$. Finally, the amino acid was dissolved in methanol, and the $\mathrm{pH}$ value was adjusted to the isoelectric point with an aqueous ammonia solution. The solvent was evaporated and the product was dried over vacuum.

2-Aminotridecanoic Acid, $4\left(C_{13} A A\right) .{ }^{1} \mathrm{H}$ NMR $\left(\mathrm{CDCl}_{3}, 300\right.$ $\mathrm{MHz}$ ), $\delta$, ppm: $0.90\left(\mathrm{t}, 3 \mathrm{H}, \mathrm{CH}_{3}\right), 1.21-1.37\left(\mathrm{~m}, 14 \mathrm{H}, \mathrm{CH}_{2}\right)$, $1.42\left(\mathrm{~m}, 2 \mathrm{H}, \mathrm{CH}_{2}\right), 1.68\left(\mathrm{~m}, 2 \mathrm{H}, \mathrm{CH}_{2}\right), 1.77\left(\mathrm{~m}, 2 \mathrm{H}, \mathrm{CH}_{2}\right)$, $3.98\left(\mathrm{t}, 1 \mathrm{H}, \mathrm{CHNH}_{2} \mathrm{COOH}\right) .{ }^{13} \mathrm{C} \mathrm{NMR}, \delta$, ppm: 180.7 (COOH), $72.7\left(\underline{\mathrm{C}} \mathrm{HNH}_{2} \mathrm{COOH}\right), 35.9-14.5\left(\mathrm{C}_{\text {alkyl }}\right) . \mathrm{HRMS}$ (ESI): $m / z 230.2115\left(\mathrm{M}+\mathrm{H}^{+}\right)$, calcd for $\mathrm{C}_{13} \mathrm{H}_{28} \mathrm{NO}_{2}^{+}$, 230.2109 .

2.2.3. Conjugation of 2-Aminotridecanoic Acid with 7Nitrobenz-2-oxa-1,3-diazol-4-yl. The lipidic amino acid was dissolved in dry chloroform with $20 \%$ methanol and excess sodium carbonate was added. NBD-Cl dissolved in the minimal amount of dry chloroform was added dropwise with constant 
stirring. The mixture was left in the dark, with stirring, for $6 \mathrm{~h}$ at room temperature. A small excess of amino acid was used with a concentration of amine $\sim 10 \mathrm{mg} / \mathrm{mL}$. The reaction mixture was purified using $\mathrm{Si} 60$ preparative TLC plates and $\mathrm{CHCl}_{3}$ / $\mathrm{MeOH} / \mathrm{CH}_{3} \mathrm{COOH}$ 80:20:1 as eluent. The product, NBD$\mathrm{C}_{13} \mathrm{AA}$ being the most intense yellow band with and a retention factor $\sim 0.2$, was extracted from the stationary phase using chloroform/methanol mixtures and further purified by preparative liquid chromatography using the stationary phase RP18 and acetonitrile/water 75:25 as eluent.

$N B D$ Conjugate of 2-Aminotridecanoic Acid (NBD-C $\left.{ }_{13} A A\right)$. ${ }^{1} \mathrm{H} \mathrm{NMR}\left(\mathrm{CD}_{3} \mathrm{OD}, 300 \mathrm{MHz}\right), \delta$, ppm: $0.89(\mathrm{t}, J=3.6 \mathrm{~Hz}, 3 \mathrm{H}$, $\left.\mathrm{CH}_{3}\right), 1.20-1.40\left(\mathrm{~m}, 18 \mathrm{H}, \mathrm{CH}_{2}\right), 1.45\left(\mathrm{~m}, 2 \mathrm{H}, \mathrm{CH}_{2}\right), 3.67(\mathrm{~m}$, $1 \mathrm{H}, \mathrm{C} \underline{\mathrm{HCOOH}}), 6.02$ (d, $J=4.8 \mathrm{~Hz}, 1 \mathrm{H}, \mathrm{NHCC} \underline{\mathrm{H}}), 8.46$ (d, $J$ $=4.8 \mathrm{~Hz}, 1 \mathrm{H}, \mathrm{CC}^{\mathrm{HNO}}{ }_{2}$ ).

2.3. Solubility of the Lipidic Amino Acid. The critical aggregation concentration $(\mathrm{CAC})$ of $\mathrm{C}_{13} \mathrm{AA}$ was determined using the method developed in ref 26 , based on the increase in the fluorescence quantum yield and shift to smaller wavelengths of $N$-phenyl-1-naphthylamine (NPN) upon association with preformed aggregates. The total concentration of NPN was 100 $\mathrm{nM}$, and the concentrations of $\mathrm{C}_{13} \mathrm{AA}$ in the aqueous buffer were changed between 0 and $100 \mu \mathrm{M}$, at $25^{\circ} \mathrm{C}$. The aqueous solutions of $\mathrm{C}_{13} \mathrm{AA}$ were prepared by addition of a small aliquot of amphiphile dissolved in methanol (the final concentration of methanol was always $0.5 \% \mathrm{v} / \mathrm{v}$ ) and the required amount of NPN dissolved in aqueous buffer with $0.5 \%$ methanol was added. Solutions were left to equilibrate for 2-4 h, and the fluorescent emission of NPN was measured using an excitation wavelength of $356 \mathrm{~nm}$.

The solubility of the monomeric form of NBD- $\mathrm{C}_{13} \mathrm{AA}$ in aqueous solutions, at $\mathrm{pH}=7.4$ and $25{ }^{\circ} \mathrm{C}$, was assessed via deviations to linearity in the amphiphile absorption and/or fluorescence as a function of the total concentration of amphiphile. The necessary volume of a solution of the amphiphile in methanol was placed in a glass tube, the solvent was evaporated under a stream of nitrogen, and the required amount of aqueous solution was added. The solutions were allowed to equilibrate at $25{ }^{\circ} \mathrm{C}$ for $2-4 \mathrm{~h}$ and their absorption and fluorescence were measured. In all measurements, the absorption (plus scatter) was smaller than 0.1 at the excitation wavelength guaranteeing a linear fluorescence response and minimizing inner filter effects. The concentration of NBD$\mathrm{C}_{13} \mathrm{AA}$ in the methanol solutions was calculated assuming $\varepsilon=$ $2.1 \times 10^{4} \mathrm{M}^{-1} \mathrm{~cm}^{-1}$ and within the experimental uncertainty the same molar absorption coefficient was observed for the amphiphile dissolved in the aqueous buffer.

2.4. Binding of NBD-C $C_{13} A A$ to $B S A$. The equilibrium constant between NBD- $\mathrm{C}_{13} \mathrm{AA}$ and $\mathrm{BSA}$ was obtained using the approach described before. ${ }^{25} \mathrm{~A}$ small aliquot of NBD-C ${ }_{13} \mathrm{AA}$, dissolved in methanol, was added to aqueous solutions with different concentrations of BSA (final concentration of methanol equal to $0.5 \%$ ) and the solutions were allowed to equilibrate for $1-2 \mathrm{~h}$. The amount of fluorescent amphiphile bound to albumin was assessed via the increase in its fluorescence upon binding.

The characterization of the binding of $\mathrm{C}_{13} \mathrm{AA}$ to $\mathrm{BSA}$ was attempted using ITC. However, the experiments were not doable due to the large heat of dilution of the protein (when adding BSA to the ligand) and the low solubility of the ligand (if the ligand was to be added to the protein).

2.5. Partition of NBD-C ${ }_{13} A A$ to POPC Bilayers Followed by Fluorescence Energy Transfer. POPC bilayers were in the form of large unilamellar vesicles (LUV) and contained diphenyl hexatriene (DPH) at a molar ratio of 1:500. A mixture of POPC and DPH in azeotropic mixture of chloroform and methanol $(87: 13, \mathrm{v} / \mathrm{v})$ was allowed to equilibrate for $1 \mathrm{~h}$ and the solvent was evaporated by blowing dry nitrogen over the heated (blowing hot air over the external surface of the tube) solution. The film was left in a vacuum desiccator for at least $8 \mathrm{~h}$ at room temperature to eliminate traces of organic solvent and then hydrated with the aqueous buffer. The hydrated lipid was subjected to several cycles of gentle vortex/incubation at room temperature for at least $1 \mathrm{~h}$, to produce a suspension of multilamelar vesicles that was then extruded in a water-jacketed extruder (Lipex Biomembranes, Vancouver, British Columbia, Canada) using a minimum of 15 passes, through two stacked polycarbonate filter (Nucleopore) with a pore diameter of $0.1 \mu \mathrm{m} .^{27}$ The radius of the different LUVs preparations was $53 \pm 4 \mathrm{~nm}$, as shown by dynamic light scattering with a volume distribution analysis. The final phospholipid concentrations in the LUVs was determined using a modified version of the Bartlett phosphate assay, ${ }^{28}$ and $\mathrm{DPH}$ was quantified by its absorption at $355 \mathrm{~nm}$ assuming $\varepsilon=$ $8.1 \times 10^{4} \mathrm{M}^{-1} \mathrm{~cm}^{-1}$. 9 NBD-C 13 AA dissolved in the aqueous buffer was added to the DPH:POPC LUVs at a total concentration of $\mathrm{NBD}-\mathrm{C}_{13} \mathrm{AA}$ equal to $4 \mu \mathrm{M}$ and lipid concentrations from 0 to $1 \mathrm{mM}$. The solutions were allowed to equilibrate for 2 to $4 \mathrm{~h}$ and DPH fluorescence was measured with a path length of $5 \mathrm{~mm}$.

2.6. Partition of NBD-C ${ }_{13} A A$ to POPC Bilayers Followed by Isothermal Titration Calorimetry. The titration was performed with additions of 10 or $20 \mu \mathrm{L}$ of the lipid solution per injection and the concentrations in the cell were calculated considering that overflow is faster than mixing. ${ }^{30}$ Amphiphilic ligands may adsorb to some equipment parts, in particular to the filling syringe, reducing the amount of ligand available. To overcome this difficulty, after cleaning thoroughly with water, the equipment cell was rinsed with a solution with the same composition as the solution to be used in the experiment before filling with the required titration solution. All solutions were previously degassed for $15 \mathrm{~min}$. The titrations were performed in aqueous solutions containing $0.15 \mathrm{M} \mathrm{NaCl}, 0.02 \% \mathrm{NaN}_{3}$, and $1 \mathrm{mM}$ EDTA. Additionally the $\mathrm{pH}$ was controlled at 7.4 with $10 \mathrm{mM}$ of HEPES, phosphate or TRIS.

For the experiments where the $\mathrm{pH}$ was controlled with HEPES or phosphate, the interaction parameters (partition coefficient and interaction enthalpy) were obtained from the best fit to the differential heat curve. ${ }^{31}$ However, for the experiments performed in TRIS buffer, the global interaction enthalpy (partition plus buffer ionization) is very small and a conventional titration curve cannot be obtained with acceptable signal-to-noise ratios. The interaction enthalpy was therefore obtained from the cumulative heat obtained for the complete partition of the amphiphile to the membrane, after subtraction of the dilution heat obtained from the addition of the lipid to the buffer in the absence of amphiphile.

Some qualitative information on the rate of translocation of the lipidic amino acid was obtained using the uptake and release protocol. ${ }^{32}$ The POPC LUVs loaded with amphiphile were prepared at a probe to lipid ratio of 1:20 via the addition of an aqueous solution of POPC at $1 \mathrm{mM}$ in phosphate buffer to a film of the amphiphile. The solution was allowed to equilibrate for $24 \mathrm{~h}$ at room temperature with occasional vortex stirring. 
2.7. Zeta Potential and Size of POPC LUVs Loaded with NBD-C ${ }_{13}$ AA. POPC LUVs in aqueous HEPES buffer without $\mathrm{NaCl}$ were prepared following the procedure indicated above. Different concentrations have been prepared and incubated with NBD-C ${ }_{13} \mathrm{AA}$ (at 4 or $18 \mu \mathrm{M}$ ) for $6 \mathrm{~h}$ at 25 ${ }^{\circ} \mathrm{C}$. The LUV solutions were always monodisperse in both size and zeta potential, their average size was evaluated from the size distribution by volume assuming $\eta=0.89 \mathrm{cP}^{33}$ and a refractive index of 1.33 .

The aqueous solution used was $10 \mathrm{mM}$ HEPES at $\mathrm{pH}=7.4$ with $\mathrm{NaN}_{3} 0.02 \%$ and $1 \mathrm{mM}$ EDTA, as in the previous sections, but without $\mathrm{NaCl}$. This decrease in the ionic strength of the solution was required to allow the measurement of the zeta potential.

\section{RESULTS AND DISCUSSION}

3.1. Synthesis of $\alpha$-Aminotridecanoic Acid. To synthesize $\alpha$-amino acids from the corresponding aldehydes obtained via hydroformylation reaction it is imperative to optimize the regioselectivity of the reaction in order to enhance the formation of the linear aldehyde. Our recent study on the optimization of the synthesis of a set of $\alpha$-amino acids via one pot hydroformylation-Strecker sequential reaction showed that the regioselectivity for linear aldehyde depends on the phosphine structure and also on the reaction conditions (pressure and temperature). ${ }^{34}$ The catalytic system that showed the best performance was $\mathrm{Rh} /$ xantphos at $80^{\circ} \mathrm{C}$ of temperature and 20 bar of pressure. Therefore, for $\alpha$-aminotridecanoic acid synthesis, the catalytic precursor $\mathrm{Rh}(\mathrm{acac})(\mathrm{CO})_{2}$ and xantphos have been introduced in the autoclave and, after air evacuation, 1-undecene (1) and toluene were introduced via cannula and finally the pressure and temperature were adjusted: step A. Aliquots were taken to acquire the end of the hydroformylation reaction before proceed to the subsequent in situ Strecker reaction: step B. After the end of the hydroformylation step (44 $\mathrm{h}$ ), the linear aldehyde (2) was obtained in $94 \%$ of yield. In order to obtain the corresponding aminonitrile (3), the reaction vessel was cooled until room temperature and stoichiometric amounts of $\mathrm{NaCN}$ and $\mathrm{NH}_{4} \mathrm{Cl}$ were added. The $\alpha$-aminotridecanonitrile (3) achieved in $83 \%$ yield was isolated and subsequently transformed into the desired lipidic amino acid (4) via hydrolysis with $\mathrm{HCl}$, Scheme 1. The $\alpha$ aminotridecanoic acid (4) obtained in 73\% yield was fully characterized by ${ }^{1} \mathrm{H}$ and ${ }^{13} \mathrm{C}$ NMR and MS analysis (the spectra are given in the additional materials).

3.2. Solubility of $\alpha$-Aminotridecanoic Acid in the Aqueous Media. The aggregation behavior of $\alpha$-amino-

\section{Scheme 1}

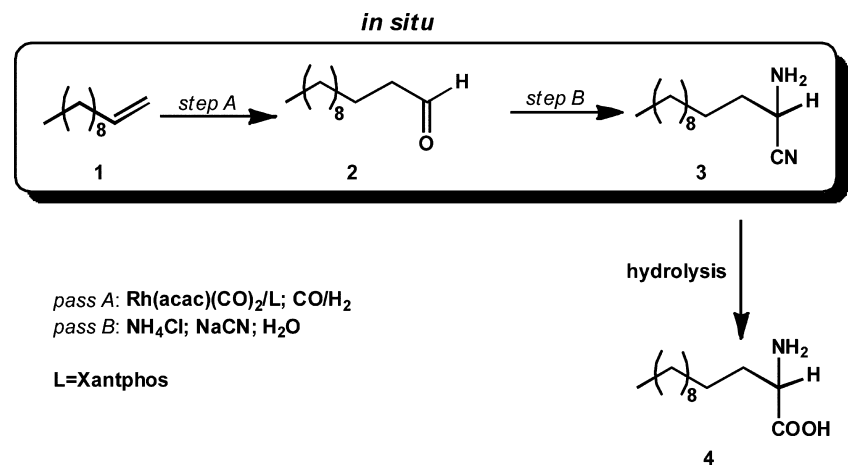

tridecanoic acid $\left(\mathrm{C}_{13} \mathrm{AA}\right)$ was studied via variation in the fluorescence of NPN due to partition to the lipidic amino acid aggregates. ${ }^{26}$ The value obtained for the critical aggregation concentration, at $25{ }^{\circ} \mathrm{C}$ (HEPES $10 \mathrm{mM} \mathrm{pH}=7.4, \mathrm{NaCl} 150$ $\mathrm{mM}$, EDTA $\left.1 \mathrm{mM}, 0.02 \% \mathrm{NaN}_{3}\right)$, was $11 \pm 5 \mu \mathrm{M}$, typical results are shown in Figure 1. Due to the low value of the
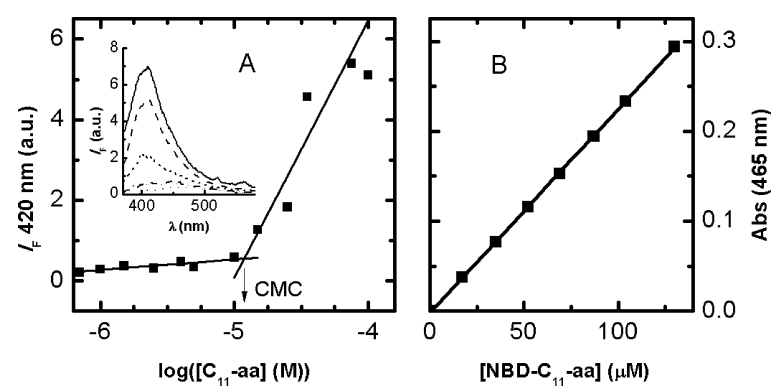

Figure 1. (A) Average of the NPN fluorescence emission between 410 and $430 \mathrm{~nm}$ in the presence of different concentrations of $\mathrm{C}_{13} \mathrm{AA}$ at 25 ${ }^{\circ} \mathrm{C}$ in the aqueous buffer solution (HEPES $10 \mathrm{mM}, \mathrm{pH}=7.4, \mathrm{NaCl}$ $150 \mathrm{mM}$, EDTA $1 \mathrm{mM}$, and $\mathrm{NaN}_{3} 0.02 \%$ ). The lines are the best fit of a straight line to each of the two regimes that intercept at the critical aggregation concentration of $\mathrm{C}_{13} \mathrm{AA}$. The inset shows the fluorescence spectra of the solutions at the amphiphile concentrations: $0(\cdots \cdots), 10$ (--), 25 (---), $35(--)$, and $75 \mu \mathrm{M}(-)$. (B) Absorption at $465 \mathrm{~nm}$ of NBD- $\mathrm{C}_{13} \mathrm{AA}$ at different concentrations in the aqueous buffer at 25 ${ }^{\circ} \mathrm{C}$. The line is the best fit of a straight line.

solubility encountered for the monomeric species, a small concentration of NPN had to be used (100 nM) leading to a rather low fluorescence intensity when dissolved in the aqueous solution $\left(\left[\mathrm{C}_{13} \mathrm{AA}\right] \leq 6 \mu \mathrm{M}\right)$. At higher amphiphile concentrations $\left(\left[\mathrm{C}_{13} \mathrm{AA}\right] \geq 15 \mu \mathrm{M}\right)$, soft aggregates are formed to which NPN partitions with a significant increase in the fluorescence quantum yield and a concomitant blue shift in the emission maxima. The critical aggregation concentration (CAC) was obtained from the intercept of the straight lines describing NPN fluorescence in the two regimes. ${ }^{26}$ The standard deviation indicated above for the CAC reflects variations observed on the intercept between the two regimes for over 10 independent experiments. The solutions above the CAC were characterized by dynamic light scattering indicating a high polydispersity index with an average diameter that increases with the amphiphile concentration. Just above the $\mathrm{CAC}$, the large majority of the amphiphile is in small aggregates with a diameter of $1-5 \mathrm{~nm}$, compatible with the formation of small micelles. As the total concentration of amphiphile is increased, the average size of the aggregates increases being centered at $300 \mathrm{~nm}$ for $\left[\mathrm{C}_{13} \mathrm{AA}\right]=30 \mu \mathrm{M}$.

The value encountered for $\mathrm{C}_{13} \mathrm{AA} \mathrm{CAC}$ is not easily compared with literature data because the aggregation behavior of lipidic amino acids has not been reported. The solubility of the monomeric form is significantly smaller than that observed for fatty acids with the same length in the hydrocarbon chain $\left(\mathrm{CMC}\left(\mathrm{C}_{11} \mathrm{COO}^{-}\right)=0.80 \mathrm{mM}^{35}\right)$ or for amino acid derived amphiphiles with a similar number of aliphatic carbons $\left(\mathrm{CMC}\left(\mathrm{C}_{11} \mathrm{Arg}^{+}\right)=5.8 \mathrm{mM},{ }^{36} \mathrm{CMC}\left(\mathrm{C}_{10} \mathrm{Cys}^{-}\right)=0.42\right.$ $\left.\mathrm{mM}^{37}\right)$. This difference is a consequence of the neutral global charge of the lipidic amino acid used in this work that reduces significantly its solubility in the aqueous media as a monomer. Additionally, its zwitterionic nature and hydrogen bonding ability stabilizes the formation of large amphiphile aggregates. 
3.3. Photophysics and Aqueous Solubility of $\alpha$ Aminotridecanoic Acid Conjugated with a Polar, DrugLike, Fluorescent Moiety (NBD-C $\left.{ }_{13} A A\right)$. Lipidic amino acids have been attached covalently to polar drugs in an attempt to enhance their bioavailability. ${ }^{10-13,16,38-41}$ In this work we have covalently attached the fluorescent moiety 7-nitrobenz-2-oxa1,3-diazol-4-yl (NBD) to the $\alpha$-amine group of compound 4 (NBD-C $\left.{ }_{13} \mathrm{AA}\right)$. The resulting secondary amine is expected to be a very weak base, ${ }^{25}$ and therefore, in aqueous solutions at $\mathrm{pH}=7.4, \mathrm{NBD}-\mathrm{C}_{13} \mathrm{AA}$ has a negative charge. The aggregation behavior of the resulting amphiphile was first studied to characterize the concentration range where it is in the monomeric form and to guarantee that it is in this state at the concentrations used in the binding experiments. It was found that this amphiphile is soluble in the aqueous solution in its monomeric state up to a concentration of at least $130 \mu \mathrm{M}$, Figure 1B. Higher concentrations were not evaluated due to limitations in the amount of amphiphile available and on the method used. Nevertheless, those results show that this derivative is significantly more soluble than the starting amino acid as expected due to its global negative charge. This amphiphile is also much more soluble than the fatty amine with the equivalent hydrocarbon chain used by these authors in previous studies $\left(\mathrm{CAC}\left(\mathrm{NBD}-\mathrm{C}_{10}\right)=0.05 \mu \mathrm{M}\right)$ its solubility being comparable to that of fatty acids with similar hydrocarbon chains $^{35}$ and to the $\mathrm{N}$-glucose conjugate of $\alpha$-aminotridecanoic acid in the anionic form. ${ }^{15}$

The absorption spectra of the NBD conjugated amino acid in aqueous solution was significantly blue-shifted as compared with that of NBD fatty amines but the molar absorption coefficient at the maximum is very similar $\left(\sim 2.1 \times 10^{4} \mathrm{M}^{-1}\right.$ $\left.\mathrm{cm}^{-1}\right)$. The fluorescence emission spectrum is red-shifted showing a significantly larger Stokes shift for the lipid amino acid conjugate, Figure 2 . The fluorescence quantum yield of

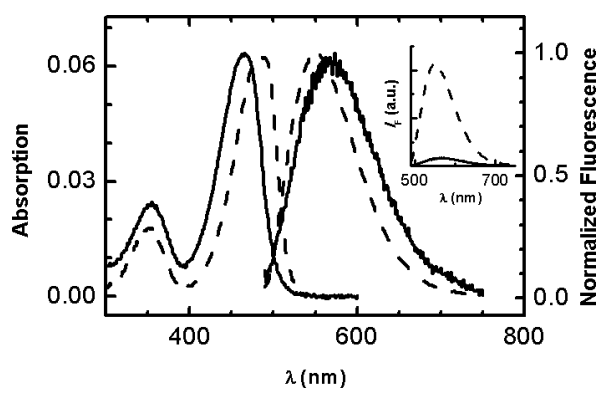

Figure 2. Absorption and normalized fluorescence emission spectra (when excited at $475 \mathrm{~nm}$ ) of NBD-C ${ }_{13} \mathrm{AA}(-)$ and NBD-C6 (----) in aqueous buffer at a concentration of $3 \mu \mathrm{M}$. The inset shows the fluorescence emission spectra without normalization highlighting the much smaller fluorescence quantum yield of NBD-C ${ }_{13} \mathrm{AA}$.

NBD- $\mathrm{C}_{13} \mathrm{AA}$ in aqueous solutions is significantly smaller than that of NBD-C $C_{n}(\sim 10$ times), see inset in Figure 2 for comparison with $\mathrm{NBD}-\mathrm{C}_{6}$, in agreement with the red shift observed.

3.4. Binding of $N B D-C_{13} A A$ to $B S A$. The rational underlying the conjugation of lipidic amino acids to polar drugs to enhance their bioavailability was the expected increase in the partition of the modified drug to biomembranes. Surprisingly, their partition coefficient between the aqueous media and lipid bilayers or their binding to blood proteins such as serum albumin has never been characterized. In this work we have studied the association of the NBD conjugate with the most abundant serum protein and the partition of both $\mathrm{C}_{13} \mathrm{AA}$ and NBD- $\mathrm{C}_{13} \mathrm{AA}$ between the aqueous phase and lipid bilayers.

The binding of NBD- $\mathrm{C}_{13} \mathrm{AA}$ to bovine serum albumin (BSA) was characterized via the increased in the fluorescence quantum yield of NBD upon binding of the amphiphile to BSA, ${ }^{25,42-44}$ Figure 3. Five independent experiments have been performed

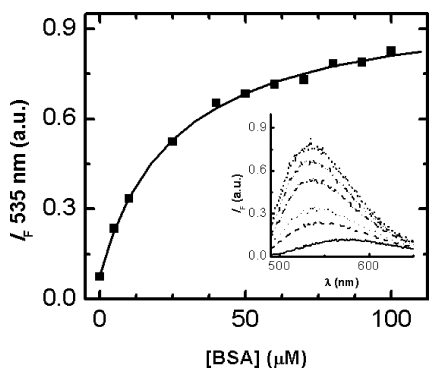

Figure 3. Binding of NBD- $\mathrm{C}_{13} \mathrm{AA}$ to $\mathrm{BSA}$ in the aqueous buffer (HEPES $10 \mathrm{mM}, \mathrm{pH}=7.4, \mathrm{NaCl} 150 \mathrm{mM}$, EDTA $1 \mathrm{mM}$ and $\mathrm{NaN}_{3}$ $0.02 \%)$ at $25{ }^{\circ} \mathrm{C}$. The fluorescence intensity was normalized to that at total amphiphile binding and the line is the best fit of eq 1 with $K_{\mathrm{B}}=$ $3.8 \times 10^{4} \mathrm{M}^{-1}$ and $\Phi_{\mathrm{AB}} / \Phi_{\mathrm{A}}=13$. The inset show the fluorescence spectra of the solutions at $\left[\mathrm{NBD}-\mathrm{C}_{13} \mathrm{AA}\right]=100 \mathrm{nM}$ and different concentrations of BSA: $0(-), 5(--), 10(\cdots \cdots), 25(--), 40(-\cdot)$, and $100 \mu \mathrm{M}(---)$.

leading to $K_{\mathrm{B}}=3.5( \pm 0.6) \times 10^{4} \mathrm{M}^{-1}$. The results were analyzed with eq 1 that describes binding of the amphiphile (A) to a single binding site at a large excess of protein (B):

$$
\begin{gathered}
I_{\mathrm{F}}=\Phi_{\mathrm{A}}[\mathrm{A}]+\Phi_{\mathrm{AB}}[\mathrm{AB}] \\
{[\mathrm{A}]=\frac{\left[\mathrm{A}_{\mathrm{T}}\right]}{1+K_{\mathrm{B}}[\mathrm{B}]} ;[\mathrm{AB}]=\frac{\left[\mathrm{A}_{\mathrm{T}}\right] K_{\mathrm{B}}[\mathrm{B}]}{1+K_{\mathrm{B}}[\mathrm{B}]}}
\end{gathered}
$$

where $K_{\mathrm{B}}$ is the binding constant and $\left[\mathrm{A}_{\mathrm{T}}\right]$ is the total concentration of amphiphile from which $[\mathrm{A}]$ is in the aqueous media and $[\mathrm{AB}]$ is bound to the protein. At the conditions used, total concentration of protein much higher than that of the amphiphile, the concentration of free protein [B] may be considered equal to its total concentration. The total fluorescence emitted by the solution is given by the concentration of amphiphile multiplied by a proportionality factor related with its fluorescence quantum yield considering both the probe in the aqueous media $\left(\Phi_{\mathrm{A}}\right)$ and bound to the protein $\left(\Phi_{\mathrm{AB}}\right)$.

3.5. Interaction of $C_{13} A A$ and NBD- $C_{13} A A$ with POPC Bilayers. 3.5.1. Equilibrium Partition Coefficient. Partition of NBD- $\mathrm{C}_{13}$ AA to POPC bilayers was also studied but could not be followed directly via variations in the fluorescence quantum yield of NBD because this parameter was not significantly affected by interactions with the membrane. We have also tried to follow the transfer from BSA to POPC bilayers but the small fluorescence intensity from the amphiphile was masked by the large scatter from the liposomes.

The amount of NBD- $\mathrm{C}_{13} \mathrm{AA}$ associated with the bilayer was evaluated from the fluorescence quenching of diphenyl hexatriene $(\mathrm{DPH})$ previously associated with the POPC bilayer at a concentration of 0.2 molar \%. The fluorescence quenching observed is due to nonradiative energy transfer from DPH to NBD when both probes are associated with the lipid bilayer as anticipated by the extensive overlap between DPH fluorescence and NBD absorption spectra, Figure 4A. Typical results obtained are shown in Figure 4B. 

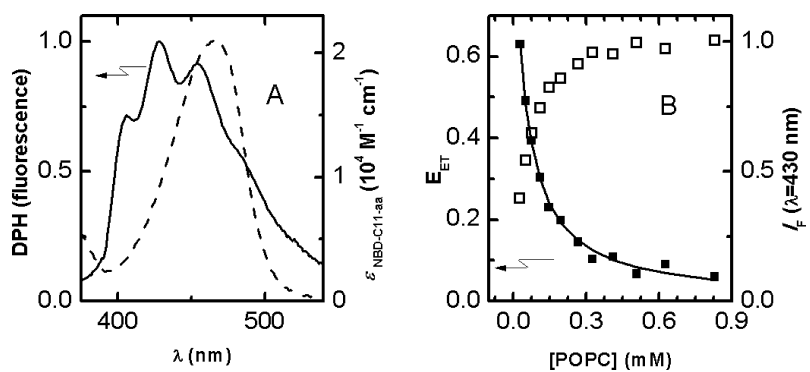

Figure 4. (A) Fluorescence emission spectra of DPH (-) and molar absorption coefficient of NBD- $\mathrm{C}_{13} \mathrm{AA}(--)$ in the presence of POPC LUVs. (B) Relative fluorescence intensity of DPH inserted in POPC bilayers due to energy transfer to NBD- $\mathrm{C}_{13} \mathrm{AA}(\square)$ and correspondent efficiency of energy transfer ( $\square$ ) calculated from eq 3 in the Supporting Information. The line is the best fit of eqs 1 and 2 in the Supporting Information for $R_{\mathrm{e}}=0$, with $K_{\mathrm{P}}=8.2 \times 10^{4}$ and $R_{0}=14 \AA$.

The dependence observed on the efficiency of energy transfer $\left(E_{\mathrm{ET}}\right)$ with the concentration of lipid was analyzed with an analytical approximation for energy transfer in two dimensions. ${ }^{45}$ Details of the model and fitting procedure may be found in the Supporting Information, together with a critical evaluation of the applicability of this model and accuracy of the parameters obtained given the information known regarding NBD and DPH photophysics ${ }^{29,46,47}$ and the location and dynamics of NBD-amphiphiles in POPC bilayers. ${ }^{20,24,25,47}$ The parameters obtained from the analysis of energy transfer results were strongly model dependent leading to a large uncertainty in the parameters obtained. Important qualitative information may still be obtained from those experiments as they undoubtedly show that the NBD moiety of the amphiphile is in close proximity to the POPC bilayer at the lipid concentrations used.

Quantitative information regarding the interaction of the amphiphiles with the POPC bilayer was obtained using isothermal titration calorimetry. A typical titration curve is

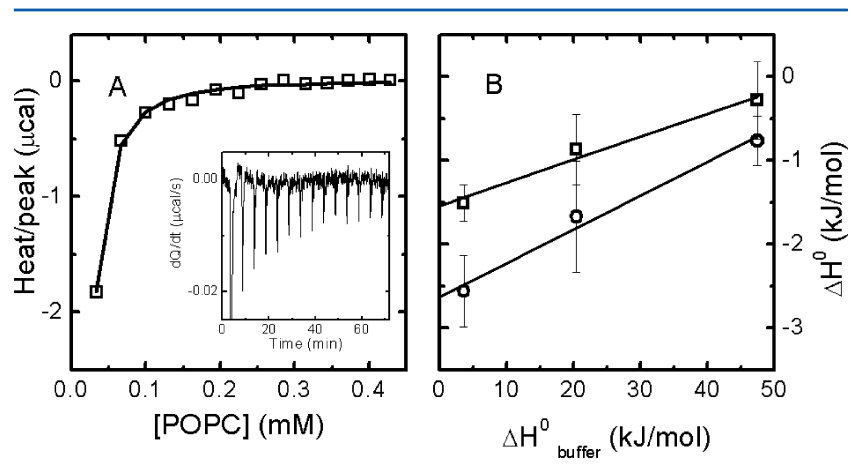

Figure 5. (A) Heat evolved due to the partition of NBD-C ${ }_{13} \mathrm{AA}$ to POPC bilayers ( $\square$ ), in HEPES buffer, and best fit assuming simple partition and all lipid accessible to the amphiphile, ${ }^{31}$ eqs 2 and 3, with $K_{\mathrm{P}}=4.6 \times 10^{4}$ and $\Delta H^{0}=-0.9 \mathrm{~kJ} / \mathrm{mol}$. The inset shows the corresponding thermogram. The amphiphile was initially at a concentration of $13 \mu \mathrm{M}$ in the cell aqueous solution and $20 \mu \mathrm{L}$ aliquots of POPC LUVs at $2.5 \mathrm{mM}$ lipid were added. (B) Dependence of the observed enthalpy variation associated with partition to POPC bilayers on the ionization enthalpy of the $\mathrm{pH}$ buffer used (phosphate, HEPES or TRIS) for NBD- $\mathrm{C}_{13} \mathrm{AA}(\square)$ and $\mathrm{C}_{13} \mathrm{AA}(\mathrm{O})$. The lines are the linear best fit to the experimental results indicating an intrinsic partition enthalpy variation $\left(\Delta H_{\mathrm{P}}^{0}\right)$ of $-1.5 \pm 0.2(-2.6 \pm 0.3) \mathrm{kJ} / \mathrm{mol}$ and $0.03(0.04) \mathrm{H}^{+}$transferred from the buffer to NBD-C $\mathrm{C}_{13} \mathrm{AA}$ $\left(\mathrm{C}_{13} \mathrm{AA}\right)$ upon partition. shown in Figure 5A. The experimental results were analyzed with a model assuming simple partition, eq 2 :

$$
n_{\mathrm{C}_{13} \mathrm{~L}}=n_{\mathrm{C}_{13} \mathrm{~T}} \frac{K_{\mathrm{P}} \bar{V}_{\mathrm{L}}[\mathrm{L}]}{1+K_{\mathrm{P}} \bar{V}_{\mathrm{L}}[\mathrm{L}]}
$$

where $n_{\mathrm{C}_{13} \mathrm{~L}}(i)$ is the number of moles of the lipidic amino acid $\left(\mathrm{C}_{13} \mathrm{AA}\right.$ or NBD-C $\left.{ }_{13} \mathrm{AA}\right)$ associated with the lipid bilayer, $n_{\mathrm{C}_{13} \mathrm{~T}}$ is the total number of moles of ligand (in the aqueous phase plus associated with the lipid bilayer), $K_{\mathrm{P}}$ is the partition coefficient, [L] is the lipid concentration and $\bar{V}_{\mathrm{L}}$ is the molar volume of the lipid $\left(0.795 \mathrm{dm}^{3} / \mathrm{mol}\right.$ for POPC $\left.{ }^{48}\right)$.

The heat evolved at each titration step $(q(i))$ was calculated from eq 3 , where $V(i)$ is the volume of the lipid solution injected in the titration step $i, V_{\text {cell }}$ is the volume of the calorimeter cell, $q_{\text {dil }}$ is the heat of dilution of the POPC LUVs, and $\Delta H^{0}$ is the enthalpy variation due to partition from the aqueous into the lipidic phase:

$$
q(i)=\Delta H^{0}\left(n_{\mathrm{C}_{13} \mathrm{~L}}(i)-n_{\mathrm{C}_{13} \mathrm{~L}}(i-1)\left(1-\frac{V(i)}{V_{\text {cell }}}\right)\right)+q_{\text {dil }}
$$

The average values obtained for NBD- $\mathrm{C}_{13} \mathrm{AA}$ from 10 titrations are $K_{\mathrm{P}}=5.0( \pm 0.9) \times 10^{4}$ and $\Delta H^{0}=-0.9 \pm 0.2 \mathrm{~kJ} / \mathrm{mol}$. We have also followed the partition of the lipidic amino acid without the NBD group $\left(\mathrm{C}_{13} \mathrm{AA}\right)$ to the POPC bilayers using ITC and the average values obtained are $K_{\mathrm{p}}=6.2( \pm 1.1) \times 10^{4}$ and $\Delta H^{0}=-1.5 \pm 0.7 \mathrm{~kJ} / \mathrm{mol}$. In contradiction with the much lower solubility of the unlabeled lipid amino acid as compared with that of $\mathrm{NBD}-\mathrm{C}_{13} \mathrm{AA}$, the affinity of $\mathrm{C}_{13} \mathrm{AA}$ to the POPC bilayers is only slightly higher. This highlights the different forces that determine the two equilibria namely the energy difference between the amphiphile in the aqueous solution as monomer and as aggregates or inserted in the lipid bilayer. The strong interactions that are established between $\mathrm{C}_{13} \mathrm{AA}$ molecules are responsible for its low solubility in aqueous solution but do not lead to significantly stronger interactions between the amphiphile and POPC as compared with those observed for NBD-C ${ }_{13} \mathrm{AA}$.

We call attention to the fact that the experimental conditions used in this section are not ideal, the lipid to amphiphile ratio at half titration is $\sim 10$, which is below the recommended minimum of $25 .^{31}$ The concentration of amphiphile could not however be decreased due to the very small enthalpy variation upon partition to the POPC membrane. At these conditions, the charge imposed by NBD- $\mathrm{C}_{13} \mathrm{AA}$ in the lipid bilayer is not negligible and the correction for electrostatic effects in the model leads to a significant increase in the partition coefficient calculated. Only the observed partition coefficient is reported because the poor signal-to-noise ratio of the data does not support the use of complicated models that depend on a large number of parameters. Additionally, the ionization state of the amphiphile is not known accurately and may be dependent on the local concentration of amphiphile that changes throughout the titration, see section 3.5.4. We estimate an increase of $40 \%$ or up to 3 times in the intrinsic partition coefficient when a global charge of -0.2 or -1 is considered.

3.5.2. Enthalpy of the Interaction. The enthalpy variation observed upon partition of the amphiphiles to the lipid bilayer is a result of both $(i)$ the interactions established in the aqueous media and inserted in the bilayer and (ii) transfer of $\mathrm{H}^{+}$ 
between the buffer and the amphiphile as a result of variations in the amphiphile ionization state upon insertion in the membrane. The partition experiment was repeated in aqueous solutions of $\mathrm{pH}$ buffers with different ionization enthalpies $\left(\Delta H_{\text {ionization }}^{0}(\right.$ phosphate $)=3.6 \mathrm{~kJ} / \mathrm{mol}, \Delta H_{\text {ionization }}^{0}($ HEPES $)=$ $20.4 \mathrm{~kJ} / \mathrm{mol}$ and $\Delta H_{\text {ionization }}^{0}$ (TRIS) $\left.=47.45\right)^{49}$ to separate the contributions from partition and changes in the ionization state. The results obtained are shown in Figure 5B and indicate that the protonated state of the lipidic amino acid is stabilized by $\sim 5 \%$ upon partition to the POPC membrane. The enthalpy variation due to partition to the bilayer is obtained from the intercept (at zero ionization enthalpy variation) and is $-1.5 \pm$ $0.2 \mathrm{~kJ} / \mathrm{mol}$ for NBD-C ${ }_{13} \mathrm{AA}$ and $-2.6 \pm 0.3 \mathrm{~kJ} / \mathrm{mol}$ for $\mathrm{C}_{13} \mathrm{AA}$. Those values are significantly smaller than the ones obtained for most amphiphiles with similar hydrocarbon chains (partition between water and lipid bilayers in the liquid disordered state at $25^{\circ} \mathrm{C}: \Delta H_{\mathrm{P}}^{0}(\mathrm{SDS})=-18 \mathrm{~kJ} / \mathrm{mol},{ }^{31,50} \Delta H_{\mathrm{P}}^{0}$ $\left(\mathrm{NBD}-\mathrm{C}_{n}\right)=-15 \mathrm{~kJ} / \mathrm{mol},{ }^{25} \Delta H_{\mathrm{P}}^{0}\left(\mathrm{C}_{11} \mathrm{COO}^{-}\right)=-10 \mathrm{~kJ} /$ $\left.\mathrm{mol}^{35}\right)$ but small interaction enthalpies have also been reported $\left(\Delta H_{\mathrm{P}}^{0}(\mathrm{DTAC})=-4.1 \mathrm{~kJ} / \mathrm{mol}^{50} \Delta H_{\mathrm{P}}^{0}\left(\right.\right.$ lysoC $\left._{10} \mathrm{PC}\right)=-0.6 \mathrm{~kJ} /$ $\left.\mathrm{mol}^{35}\right)$.

The parameters obtained for the solubility of the amphiphiles and their association with BSA and POPC bilayers are collected in Table 1 .

Table 1. Parameters Obtained for the Solubility of the Lipidic Amino Acid $\left(\mathrm{C}_{13} \mathrm{AA}\right)$ and Its NBD Derivative (NBD$\left.\mathrm{C}_{13} \mathrm{AA}\right)$ and for Their Interaction with BSA and POPC Bilayers at $25^{\circ} \mathrm{C}$

\begin{tabular}{lccccc} 
& & \multicolumn{2}{c}{ binding to BSA } & & \multicolumn{2}{c}{ partition to POPC } \\
\cline { 5 - 6 } \cline { 5 - 6 } & CAC $(\mu \mathrm{M})$ & $K_{\mathrm{B}}\left(10^{4} \mathrm{M}^{-1}\right)$ & & $K_{\mathrm{p}}\left(10^{4}\right)^{a}$ & $\begin{array}{c}\Delta H_{\mathrm{p}}^{0} \\
(\mathrm{~kJ} / \mathrm{mol})\end{array}$ \\
$\mathrm{C}_{13} \mathrm{AA}$ & $11 \pm 5$ & & & $6.2( \pm 1.1)$ & $-2.6( \pm 0.3)$ \\
$\mathrm{NBD} \mathrm{C}_{13} \mathrm{AA}$ & $\geq 130$ & $3.5( \pm 0.6)$ & & $5.0( \pm 0.9)$ & $-1.5( \pm 0.2)$
\end{tabular}

${ }^{a}$ The indicated partition coefficient was obtained by ITC at zero enthalpy of ionization for the buffer, electrostatic effects were not considered. $^{31}$

3.5.3. Rate of Translocation of $C_{13} A A$ through $P O P C$ Bilayers. Qualitative information regarding the rate of translocation of $\mathrm{C}_{13} \mathrm{AA}$ through POPC bilayers was obtained using the Uptake and Release protocol. ${ }^{32}$ This method relies on differences between the total lipid (and amphiphile) concentration and the effective concentration $\left([\mathrm{L}]^{*}\right.$ and $\left.\left[\mathrm{C}_{13}\right]^{*}\right)$ that is available for the equilibration of the amphiphile between the aqueous and lipidic phases during the time of the experiment and allows the calculation of the equilibration factor $(\gamma)$, eq 4. ${ }^{19,32}$

$$
\begin{aligned}
& {[\mathrm{L}]^{*}(i)=[\mathrm{L}]^{*}(i-1)\left\{1-\frac{V(i)}{V_{\text {cell }}}\right\}+\gamma\left\{[\mathrm{L}]^{\text {syr }} \frac{V(i)}{V_{\text {cell }}}\right\} } \\
& n_{\mathrm{C}_{13} \mathrm{~T}}^{*}(i)= n_{\mathrm{C}_{13} \mathrm{~T}}^{*}(i-1)\left\{1-\frac{V(i)}{V_{\text {cell }}}\right\} \\
&+\left\{\gamma\left[C_{13}\right]_{L}^{\text {syr }}+\left[\mathrm{C}_{13}\right]_{\mathrm{W}}^{\text {syr }}\right\} V(i)
\end{aligned}
$$

The equilibration factor was obtained through the global best fit of eqs 3 and 4, with the moles of amphiphile in the lipidic phase being calculated from eq 2 , to the results from the uptake and release experiments. ${ }^{19}$ Typical results are shown in Figure 6.

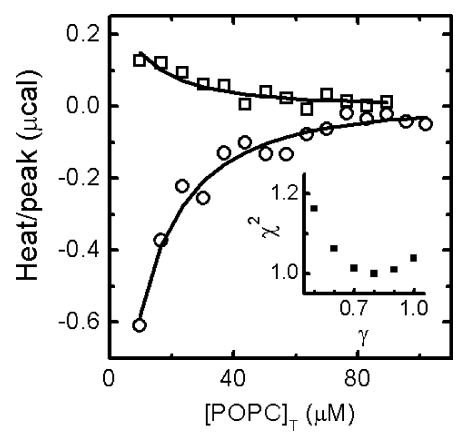

Figure 6. Heat evolved due to the addition of POPC LUVs to $5 \mu \mathrm{M}$ $\mathrm{C}_{13} \mathrm{AA}$ in phosphate buffer $(\mathrm{O})$ and due to the dilution of $\mathrm{C}_{13} \mathrm{AA} /$ POPC 1:20 into phosphate buffer $(\square)$, as a function of the total concentration of POPC in the cell. The lines are the global best fit with $K_{\mathrm{P}}=6.0 \times 10^{4}, \Delta H^{0}=-2.5 \mathrm{~kJ} / \mathrm{mol}$, and $\gamma=0.8$. The inset shows the dependence of the global fit squared residues as a function of the fraction of lipid accessible $(\gamma)$.

The value obtained for $\gamma$ in the experiments with the partition of $\mathrm{C}_{13} \mathrm{AA}$ is $0.7 \pm 0.1$. The equilibration factor has a clear physical meaning for values equal to 0.5 (only the lipid in the outer monolayer is accessible to the amphiphile in the uptake experiment and only the amphiphile in the outer monolayer is able to equilibrate with the aqueous media in the release experiment; slow translocation) and 1 (the amphiphile is able to equilibrate between the aqueous media and all the lipidic phase (outer and inner monolayer); fast translocation). Intermediate values are obtained when the amphiphile translocates only partially during the time of the experiment (200 s per peak in this work). The value obtained for $\mathrm{C}_{13} \mathrm{AA}, \gamma$ $=0.7$, indicates that the rate of translocation is within the range $10^{-2}$ to $10^{-3} \mathrm{~s}^{-1}$.

This approach could not be followed for the case of NBD$\mathrm{C}_{13} \mathrm{AA}$ due to the very small enthalpy variation upon partition to the POPC bilayer. The translocation of this amphiphile is however expected to be fast, when compared to the characteristic time for the titration experiment $(\tau \approx 10 \mathrm{~s})$, given that fatty acids translocate through bilayers in the liquid disorder state with characteristic times smaller than $2 \mathrm{~s}^{51-53}$ and that the neutral amphiphile NBD- $\mathrm{C}_{12}$ shows a characteristic time for translocation equal to $3 \mathrm{s.}{ }^{20}$ Additionally, we find that most carboxylic acid is in the neutral form when NBD- $\mathrm{C}_{13} \mathrm{AA}$ is inserted in the lipid bilayers, section 3.5.4.

We have recently shown that, for amphiphiles that translocate in the time scale of the titration experiment, quantitative information may be obtained from the time dependence of the heat evolved during each titration step. ${ }^{19}$ Unfortunately, the very small interaction enthalpy variation upon partition of this amphiphile to the POPC bilayer leads to a low signal-to-noise ratio that makes this analysis unfeasible.

3.5.4. Effect of the Amphiphiles on the Charge and Size of the POPC LUVs. We have measured the zeta potential $(\zeta)$ of the LUVs at different lipid-to-NBD-C ${ }_{13} \mathrm{AA}$ ratios to have further insight regarding the ionization state of the amphiphile when inserted in the POPC bilayer and complement the data obtained in section 3.5.2. The size of the liposomes was also measured to inspect for eventual LUVs disruption at the relatively high local concentration of amphiphile used in the previous sections. Typical results are shown in Figure 7.

The surface concentration of $\mathrm{NBD}-\mathrm{C}_{13} \mathrm{AA}$ was calculated from the partition coefficient obtained by ITC. This allows the prediction of the charge density at the surface of the bilayer as a 

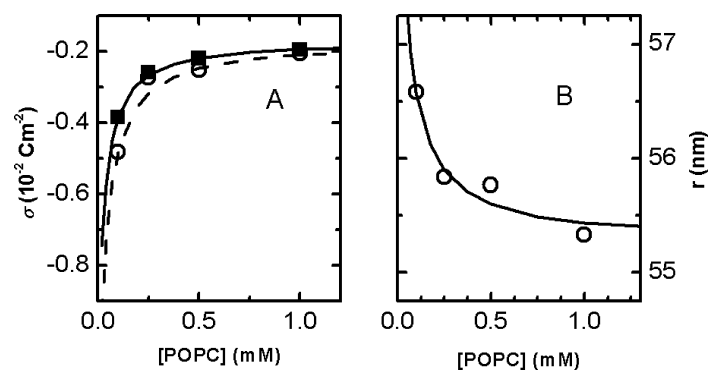

Figure 7. Surface charge density (A) and liposome radius (B) of POPC LUVs as a function of the lipid concentration, for a total concentration of NBD-C $\mathrm{C}_{13} \mathrm{AA}$ equal to $4(\boldsymbol{\square})$ or $18(\mathrm{O}) \mu \mathrm{M}$ previously incubated with the liposomes for $6 \mathrm{~h}$. The lines are the best fit assuming the partition coefficient obtained by ITC, $K_{\mathrm{P}}=5 \times 10^{4}$, see text for the model used and the values of the other parameters required.

function of the fractional charge of the amphiphile when inserted in the bilayer. From the measured zeta potential it is possible to calculate the surface potential ${ }^{54}$ and this allows in turn the calculation of the surface charge density. ${ }^{19,31}$ It should be noted that the calculation of the surface potential from the zeta potential requires the knowledge of the distance between the surface of the membrane and the plane of shear. We have used $2 \AA$ for this distance as is generally accepted, ${ }^{54}$ although this value is not well supported by experimental or theoretical work and is therefore subject to a very large uncertainty.

The minimization of the square deviation between the surface charge density calculated from (i) the amphiphile charge and partition coefficient and (ii) the surface potential allows the finding of the best partition coefficient and fractional charge of the amphiphile in the membrane. The lines shown in Figure $6 \mathrm{~A}$ are the best fit assuming the partition coefficient from ITC, and lead to a fractional charge for NBD- $\mathrm{C}_{13} \mathrm{AA}$ of -0.29 and -0.11 for a total concentration equal to 4 and 18 $\mu \mathrm{M}$, respectively. The sensitivity of the squared residuals on the parameter values is however quite shallow down to $K_{\mathrm{P}}=2 \times$ $10^{4}$ where the calculated fractional charge is -0.4 and -0.15 for a total concentration of NBD- $\mathrm{C}_{13} \mathrm{AA}$ equal to 4 and $18 \mu \mathrm{M}$, respectively. Those results show that, at the low ionic strength used in these experiments, the global charge of NBD- $\mathrm{C}_{13} \mathrm{AA}$ inserted in the POPC bilayer is negative but deviates significantly from -1 . It also shows that the local concentration of amphiphile affects significantly its ionization as expected from the surface potential generated by the charged amphiphile. The global charge of the amphiphile is expected to be somewhat more negative at the higher ionic strength used in the previous sections that are representative of physiological fluids.

The size of the POPC LUVs incubated with $18 \mu \mathrm{M}$ of NBD$\mathrm{C}_{13} \mathrm{AA}$ was also measured. The samples were all monodisperse and the average size is shown in Figure 6B. A small but significant increase is observed as the concentration of POPC is decreased (larger ratio of ligand to lipid) in agreement with the insertion of the amphiphile in the bilayer. The radius of the liposome may be calculated from the total number of amphiphile $\left(n_{\mathrm{AL}}\right)$ and phospholipid $\left(n_{\mathrm{L}}\right)$ molecules in the liposome and their respective areas $\left(A_{\mathrm{L}}\right.$ and $\left.A_{\mathrm{AL}}\right)$, eq 5 . The line shown in plot $\mathrm{B}$ is the best fit of eqs 5 and 2 assuming $63 \AA^{2}$ for the area of $\mathrm{POPC}^{55}$ and the partition coefficient obtained by ITC. The area occupied by NBD- $\mathrm{C}_{13} \mathrm{AA}$ when inserted in the bilayer was obtained as an adjustable parameter being $25 \AA^{2}$.

$$
r_{\mathrm{LUV}}=\sqrt{\frac{A_{\mathrm{LUV}}^{\mathrm{o}}}{4 \pi}} ; \quad A_{\mathrm{LUV}}^{\mathrm{o}}=\frac{A_{\mathrm{L}} n_{\mathrm{L}}+A_{\mathrm{AL}} n_{\mathrm{AL}}}{2}
$$

\section{CONCLUSIONS}

The multicomponent sequential reaction based on the hydroformylation of 1-undecene followed by the classic Strecker reaction using the $\mathrm{Rh} /$ xantphos as catalysts revealed to be a selective and green approach to synthesize lipid aminoacids, namely $\alpha$-aminotridecanoic acid.

The aqueous solubility of the lipidic amino acid covalently modified with the NBD group (NBD-C $\mathrm{C}_{13} \mathrm{AA}$ ) is comparable to that of fatty acids with similar hydrocarbon chains ${ }^{35}$ and to $\mathrm{N}$ glucose derivatives of $\mathrm{C}_{13} \mathrm{AA}^{15}$ being much higher than that of the unconjugated lipidic $\alpha$-amino acid. The NBD conjugate is much more soluble in aqueous media than NBD-fatty amines with the same alkyl length being similar to those with 4 or 6 carbons in the alkyl chain $\left[\mathrm{NBD}-\mathrm{C}_{4}\right.$ and NBD-C ${ }_{6}$ (some of the numbers indicated in Table 1 of publication 25 are incorrect due to typing errors; for $\mathrm{NBD}-\mathrm{C}_{6}$, the value encountered experimentally for the CAC was $1.3( \pm 0.1) \times 10^{-5} \mathrm{M}$ and for $\mathrm{NBD}^{-\mathrm{C}_{8}}, \mathrm{CAC}=9.1( \pm 1.2) \times 10^{-7} \mathrm{M}$ and $K_{\mathrm{B}}=5.2 \pm 0.3 \times$ $10^{5} \mathrm{M}^{-1}$, as shown in the reference figures) $]_{,}^{25}$ indicating that the longer alkyl chain in the lipidic amino acid is compensated by the presence of the carboxylic group in the polar region of the molecule. In agreement with those results, the value obtained for the binding constant between the lipidic amino acid and BSA is between those encountered for NBD-C $\mathrm{C}_{4}$ and NBD-C ${ }_{6}{ }^{25}$ However, the partition of the lipidic amino acid to the POPC bilayers is much more efficient than for the case of NBD- $\mathrm{C}_{4}$ or NBD- $\mathrm{C}_{6}$ being comparable to that obtained for NBD- $C_{8}$. This difference is a result of a more favorable interaction between the lipidic amino acid derivative and the lipid bilayer and highlight the difficulty in the prediction of the bioavailability of a given amphiphile from a single estimator of their global hydrophobicity (such as its solubility in the aqueous media, binding to serum proteins, partition between organic solvents and water or partition to lipid bilayers). However, the complete characterization of the interaction of all drugs with all binding agents in the blood and cell membranes is not feasible. It is therefore of high importance the detailed characterization of some selected amphiphilic drugs to allow the establishment of rules that may be used to predict the behavior of unrelated drugs.

The parameters obtained indicate that the conjugation of drugs with lipidic amino acids is a very promising approach to increase their bioavailability because a good aqueous solubility is maintained while the affinity for biological membranes is strongly increased. We have also observed a relatively weak binding to serum proteins, which further improves their potential use to increase the bioavailability and pharmacokinetics of polar drugs.

\section{ASSOCIATED CONTENT}

\section{S Supporting Information}

Details on the synthesis of $\mathrm{C}_{13} \mathrm{AA}$ and $\mathrm{NBD}-\mathrm{C}_{13} \mathrm{AA}$, as well as the characterization of final products and intermediates by ${ }^{1} \mathrm{H}$ $\mathrm{NMR}$, are given. The model used to analyze quantitatively the partition of NBD- $\mathrm{C}_{13} \mathrm{AA}$ to POPC bilayers via energy transfer from $\mathrm{DPH}$ is also given. This material is available free of charge via the Internet at http://pubs.acs.org. 


\section{AUTHOR INFORMATION}

\section{Corresponding Author}

*Phone: (+351) 239 854481. Fax: (+351) 239 827703. E-mail: mmoreno@ci.uc.pt.

\section{Notes}

The authors declare no competing financial interest.

\section{ACKNOWLEDGMENTS}

We thank Fundação para a Ciência e Tecnologia (COMPETE Programa Operacional Factores de Competitividade), QREN/ FEDER (PTDC/QUI-QUI/112913/2009 and PTDC/QUI/ 64565), and for the integrated action E-07/12. A.A., A.P., H.F., and F.C.-G. thank FCT for their Grants (SFRH/BD/73190/ 2010, SFRH/BPD/72126/2010, SFRH/BD/65375/2009 and SFRH/BD/40778/2007, respectively) and the Spanish Ministry of Science and Innovation (BFU2010-19451 and PRIAIBPT-2011-1025). The authors thank Joana Valério and Eurico Melo, and the Instituto de Tecnologia Química e Biológica in Oeiras (Portugal), for the facility and help in the measurement of the liposomes size and zeta potential.

\section{REFERENCES}

(1) Wilke, D. V.; Jimenez, P. C.; Araujo, R. M.; da Silva, W. M. B.; Pessoa, O. D. L.; Silveira, E. R.; Pessoa, C.; de Moraes, M. O.; Skwarczynski, M.; Simerska, P.; Toth, I.; Costa-Lotufo, L. V. ProApoptotic Activity of Lipidic Alpha-Amino Acids Isolated from Protopalythoa variabilis. Bioorg. Med. Chem. 2010, 18, 7997-8004.

(2) Testa, B.; Mayer, J. M. In Pharmacokinetic Optimization in Drug Research. Biological, Physicochemical, and Computational Strategies; Testa, B., Waterbeemb, G. F., Guy, R., Eds.; Verlag Helvetica Chimica Acta: Zurich, 2001; pp 85-95.

(3) Sengupta, P.; Hammond, A.; Holowka, D.; Baird, B. Structural Determinants for Partitioning of Lipids and Proteins Between Coexisting Fluid Phases in Giant Plasma Membrane Vesicles. Biochim. Biophys. Acta, Biomembr. 2008, 1778, 20-32.

(4) Estronca, L. M. B. B.; Moreno, M. J.; Abreu, M. S. C.; Melo, E.; Vaz, W. L. C. Solubility of Amphiphiles in Membranes: Influence of Phase Properties and Amphiphile Head Group. Biochem. Biophys. Res. Commun. 2002, 296, 596-603.

(5) Clapes, P.; Infante, M. R. Amino Acid-Based Surfactants: Enzymatic Synthesis, Properties and Potential Applications. Biocatal. Biotransform. 2002, 20, 215-233.

(6) Najera, C. From $\alpha$-Amino Acids to Peptides: All You Need for the Journey. Synlett 2002, 1388-1403.

(7) Strecker, A. Ueber die Künstliche Bildung der Milchsäure und Einen Neuen, dem Glycocoll Homologen Körper. Justus Liebigs Annal. Chem. 1850, 75, 27-45.

(8) Fernandez, E.; Castillon, S. Rhodium Catalyzed Hydroformylation; Kluwer Academic Publishers: Dordrecht, 2000; Vol. 22.

(9) Subhani, M. A.; Muller, K. S.; Koc, F.; Eilbracht, P. A New OnePot Hydroformylation/Strecker Synthesis As a Versatile Synthetic Tool for Polyfunctional Compounds and Functionalization of Dendrimers. Org. Biomol. Chem. 2009, 7, 4000-4008.

(10) Toth, I.; Hughes, R. A.; Ward, P.; McColm, A. M.; Cox, D. M.; Anderson, G. J.; Gibbons, W. A. Fatty Peptides 0.6. Penicillin and Cephalosporin Esters with Increased Lipophilic Character. Int. J. Pharm. 1991, 77, 13-20.

(11) Toth, I. A Novel Chemical Approach to Drug-Delivery - Lipidic Amino-Acid Conjugates. J. Drug Target. 1994, 2, 217-239.

(12) Toth, I.; Hillery, A. M.; Wood, I. P.; Magnusson, C.; Artursson, P. Oral Absorption of Lipidic Amino-Acid Conjugates. Int. J. Pharm. 1994, 102, 223-230.

(13) Pignatello, R.; Toth, I.; Puglisi, G. Structural Effects of Lipophilic Methotrexate Conjugates on Model Phospholipid Biomembranes. Thermochim. Acta 2001, 380, 255-264.
(14) Blanchfield, J. T.; Dutton, J. L.; Hogg, R. C.; Gallagher, O. P.; Craik, D. J.; Jones, A.; Adams, D. J.; Lewis, R. J.; Alewood, P. F.; Toth, I. Synthesis, Structure Elucidation, In Vitro Biological Activity, Toxicity, and Caco-2 Cell Permeability of Lipophilic Analogues of $\alpha$-Conotoxin MII. J. Med. Chem. 2003, 46, 1266-1272.

(15) Ross, B. P.; Decruz, S. E.; Lynch, T. B.; Davis-Goff, K.; Toth, I. Design, Synthesis, and Evaluation of a Liposaccharide Drug Delivery Agent: Application to the Gastrointestinal Absorption of Gentamicin. J. Med. Chem. 2004, 47, 1251-1258.

(16) Pignatello, R.; Guccione, S.; Castelli, F.; Sarpietro, M. G.; Giurato, L.; Lombardo, M.; Puglisi, G.; Toth, I. Enhancement of Drug Affinity for Cell Membranes by Conjugation with Lipoamino Acids II. Experimental and Computational Evidence using Biomembrane Models. Int. J. Pharm. 2006, 310, 53-63.

(17) Falconer, R. A.; Toth, I. Design, Synthesis and Biological Evaluation of Novel Lipoamino Acid-based Glycolipids for Oral Drug Delivery. Bioorg. Med. Chem. 2007, 15, 7012-7020.

(18) Andreas, M.; Peter, P. 110 Years of the Meyer-Overton Rule: Predicting Membrane Permeability of Gases and Other Small Compounds. ChemPhysChem 2009, 10, 1405-1414.

(19) Martins, P. T.; Velazquez-Campoy, A.; Vaz, W. L. C.; Cardoso, R. M. S.; Valerio, J.; Moreno, M. J. Kinetics and Thermodynamics of Chlorpromazine Interaction with Lipid Bilayers: Effect of Charge and Cholesterol. J. Am. Chem. Soc. 2012, 134, 4184-4195.

(20) Cardoso, R. M. S.; Martins, P. A. T.; Gomes, F.; Doktorovova, S.; Vaz, W. L. C.; Moreno, M. J. Chain-Length Dependence of Insertion, Desorption, and Translocation of a Homologous Series of 7Nitrobenz-2-oxa-1,3-diazol-4-yl-Labeled Aliphatic Amines in Membranes. J. Phys. Chem. B 2011, 115, 10098-10108.

(21) Kramer, S. D.; Lombardi, D.; Primorac, A.; Thomae, A. V.; Wunderli-Allenspach, $\mathrm{H}$. Lipid-Bilayer Permeation of Drug-Like Compounds. Chem. Biodiversity 2009, 6, 1900-1916.

(22) Jing, P.; Rodgers, P. J.; Amemiya, S. High Lipophilicity of Perfluoroalkyl Carboxylate and Sulfonate: Implications for Their Membrane Permeability. J. Am. Chem. Soc. 2009, 131, 2290-2296.

(23) Filipe, H.; Salvador, A.; Vaz, W.; Moreno, M. J. Quantitative Modeling of Passive Permeation through the Blood Brain Barrier. Biophys. J. 2009, 96, 146 .

(24) Filipe, H. A. L.; Moreno, M. J.; Loura, L. M. S. Interaction of 7Nitrobenz-2-oxa-1,3-diazol-4-yl-Labeled Fatty Amines with 1-Palmitoyl, 2-Oleoyl-sn-glycero-3-phosphocholine Bilayers: A Molecular Dynamics Study. J. Phys. Chem. B 2011, 115, 10109-10119.

(25) Cardoso, R. M. S.; Filipe, H. A. L.; Gomes, F.; Moreira, N. D.; Vaz, W. L. C.; Moreno, M. J. Chain Length Effect on the Binding of Amphiphiles to Serum Albumin and to POPC Bilayers. J. Phys. Chem. B 2010, 114, 16337-16346.

(26) Brito, R. M. M.; Vaz, W. L. C. Determination of the Critical Micelle Concentration of Surfactants Using the Fluorescent-Probe $\mathrm{N}$ Phenyl-1-naphthylamine. Anal. Biochem. 1986, 152, 250-255.

(27) Hope, M. J.; Bally, M. B.; Webb, G.; Cullis, P. R. Production of Large Unilamellar Vesicles by a Rapid Extrusion Procedure Characterization of Size Distribution, Trapped Volume and Ability to Maintain a Membrane-Potential. Biochim. Biophys. Acta 1985, 812, $55-65$.

(28) Bartlett, G. R. Phosphorus Assay in Column Chromatography. J. Biol. Chem. 1959, 234, 466-468.

(29) Trotter, P. J.; Storch, J. 3-[P-(6-Phenyl)-1,3,5-hexatrienyl]phenylpropionic Acid (PA-DPH) - Characterization as a Fluorescent Membrane Probe and Binding to Fatty-Acid Binding-Proteins. Biochim. Biophys. Acta 1989, 982, 131-139.

(30) Freire, E.; Schon, A.; Velazquez-Campoy, A. Biothermodynamics. Methods in Enzymology; Academic Press: New York, 2009; Vol. 455, pp 127-155.

(31) Moreno, M. J.; Bastos, M.; Velazquez-Campoy, A. Partition of Amphiphilic Molecules to Lipid Bilayers by ITC. Anal. Biochem. 2010, 399, 44-47.

(32) Tsamaloukas, A. D.; Keller, S.; Heerklotz, H. Uptake and Release Protocol for Assessing Membrane Binding and Permeation by 
way of Isothermal Titration Calorimetry. Nat. Protoc. 2007, 2, 695704.

(33) Ozbek, H. Viscosity of Aqueous Sodium Chloride Solutions from 0 to $150^{\circ} \mathrm{C}, L B N L$ Paper LBL-5931; Lawrence Berkeley National Laboratory: Washington, DC, 2010; Vol. 2011.

(34) Peixoto, A. F., Desenvolvimento de Novos Catalisadores de Metais de Transição. atálise de reações de carbonilação conducentes à obtenção de produtos de valor acrescentado. Ph.D. Thesis, Chemistry Department, University of Coimbra, Coimbra, 2010, https:// estudogeral.sib.uc.pt/bitstream/10316/17793/1/Tese_ Andreia\%20Peixoto.pdf.

(35) Hoyrup, P.; Davidsen, J.; Jorgensen, K. Lipid Membrane Partitioning of Lysolipids and Fatty Acids: Effects of Membrane Phase Structure and Detergent Chain Length. J. Phys. Chem. B 2001, 105, 2649-2657.

(36) Moran, C.; Clapes, P.; Comelles, F.; Garcia, T.; Perez, L.; Vinardell, P.; Mitjans, M.; Infante, M. R. Chemical Structure/Property Relationship in Single-Chain Arginine Surfactants. Langmuir 2001, 17, 5071-5075.

(37) Yoshimura, T.; Sakato, A.; Tsuchiya, K.; Ohkubo, T.; Sakai, H.; Abe, M.; Esumi, K. Adsorption and Aggregation Properties of Amino Acid-Based $N$-Alkyl Cysteine Monomeric and $N, N^{\prime}$-Dialkyl Cystine Gemini Surfactants. J. Colloid Interface Sci. 2007, 308, 466-473.

(38) Toth, I.; Hughes, R. A.; Munday, M. R.; Murphy, C. A.; Mascagni, P.; Gibbons, W. A. Lipidic Peptides 0.2. Synthesis, Activity and Transport of Antiinflammatory Benzoquinolizine-Lipidic Peptide Conjugates. Int. J. Pharm. 1991, 68, 191-198.

(39) Toth, I.; Griffith, I. P.; Fernandez, E. D.; Hafeez, R. A.; Holley, J. L.; Ward, P.; Gibbons, W. A. Lipidic Peptides 0.8. Cellular Uptake Studies of Lipidic Amino-Acid, Its Oligomers and Highly Lipophilic Drug Conjugates. Int. J. Pharm. 1992, 79, 39-45.

(40) Flinn, N.; Coppard, S.; Toth, I. Oral Absorption Studies of Lipidic Conjugates of Thyrotropin Releasing Hormone (TRH) and Luteinizing Hormone-Releasing Hormone (LHRH). Int. J. Pharm. 1996, 137, 33-39.

(41) Blanchfield, J.; Toth, I. Lipid, Sugar and Liposaccharide Based Delivery Systems 2. Curr. Med. Chem. 2004, 11, 2375-2382.

(42) Martins, P. A.; Gomes, F.; Vaz, W. L. C.; Moreno, M. J. Binding of Phospholipids to $\alpha$-Lactoglobulin and Their Transfer to Lipid Bilayers. Biochim. Biophys. Acta 2008, 1778, 1308-1315.

(43) Sampaio, J. L.; Moreno, M. J.; Vaz, W. L. C. Kinetics and Thermodynamics of Association of a Fluorescent Lysophospholipid Derivative with Lipid Bilayers in Liquid-Ordered and LiquidDisordered Phases. Biophys. J. 2005, 88, 4064-4071.

(44) Abreu, M. S. C.; Moreno, M. J.; Vaz, W. L. C. Kinetics and Thermodynamics of Association of a Phospholipid Derivative with Lipid Bilayers in Liquid-Disordered and Liquid-Ordered Phases. Biophys. J. 2004, 87, 353-365.

(45) Wolber, P. K.; Hudson, B. S. Analytic Solution to the Forster Energy-Transfer Problem in Two Dimensions. Biophys. J. 1979, 28, $197-210$.

(46) Prendergast, F. G.; Haugland, R. P.; Callahan, P. J. 1-[4(Trimethylamino)phenyl]-6-phenylhexa-1,3,5-triene - Synthesis, Fluorescence Properties, and Use as a Fluorescence Probe of Lipid Bilayers. Biochemistry 1981, 20, 7333-7338.

(47) Loura, L. M. S.; Carvalho, A. J. P.; Ramalho, J. P. P. Direct Calculation of Forster Orientation Factor of Membrane Probes by Molecular Simulation. J. Mol. Struct.: THEOCHEM 2010, 946, 107112.

(48) Wiener, M. C.; White, S. H. Structure of a Fluid Dioleoylphosphatidylcholine Bilayer Determined by Joint Refinement of X-ray and Neutron-Diffraction Data 0.2. Distribution and Packing of Terminal Methyl-Groups. Biophys. J. 1992, 61, 428-433.

(49) Goldberg, R. N.; Kishore, N.; Lennen, R. M. Thermodynamic Quantities for the Ionization Reactions of Buffers. J. Phys. Chem. Ref. Data 2002, 31, 231-370.

(50) Beck, A.; Li-Blatter, X.; Seelig, A.; Seelig, J. On the Interaction of Ionic Detergents with Lipid Membranes Thermodynamic Comparison of $n$-Alkyl- $\left.(+) \mathrm{N}\left(\mathrm{CH}_{3}\right)\right)\left({ }_{3}\right)$ and $n$-Alkyl-SO $\left.{ }_{4}\right)(-)$. J. Phys. Chem. B 2010, 114, 15862-15871.

(51) Kamp, F.; Westerhoff, H. V.; Hamilton, J. A. Movement of Fatty-Acids, Fatty-Acid Analogs, and Bile-Acids Across PhospholipidBilayers - Kinetics of Fatty Acid-Mediated Proton Movement Across Small Unilamellar Vesicles. Biochemistry 1993, 32, 11074-11086.

(52) Simard, J. R.; Pillai, B. K.; Hamilton, J. A. Fatty Acid Flip-Flop in a Model Membrane is Faster than Desorption into the Aqueous Phase. Biochemistry 2008, 47, 9081-9089.

(53) Carley, A. N.; Kleinfeld, A. M. Flip-Flop Is the Rate-Limiting Step for Transport of Free Fatty Acids across Lipid Vesicle Membranes. Biochemistry 2009, 48, 10437-10445.

(54) Matos, C.; de Castro, B.; Gameiro, P.; Lima, J.; Reis, S. ZetaPotential Measurements as a Tool to Quantify the Effect of Charged Drugs on the Surface Potential of Egg Phosphatidylcholine Liposomes. Langmuir 2004, 20, 369-377.

(55) Smaby, J. M.; Momsen, M. M.; Brockman, H. L.; Brown, R. E. Phosphatidylcholine Acyl Unsaturation Modulates the Decrease in Interfacial Elasticity Induced by Cholesterol. Biophys. J. 1997, 73, $1492-1505$. 